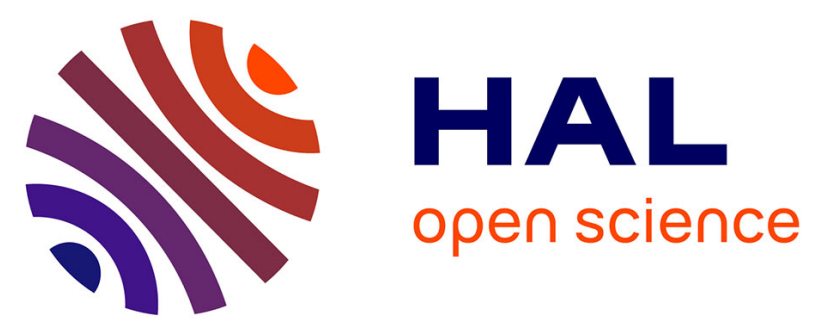

\title{
Contribution of the Faraday cup coupled to 1012 ohms current amplifier for uranium 235/238 and 234/238 isotope ratio measurements by Thermal Ionization Mass Spectrometry
}

Alexandre Quemet, Melody Maloubier, Vincent Dalier, Alexandre Ruas

\section{To cite this version:}

Alexandre Quemet, Melody Maloubier, Vincent Dalier, Alexandre Ruas. Contribution of the Faraday cup coupled to $1012 \mathrm{ohms}$ current amplifier for uranium 235/238 and 234/238 isotope ratio measurements by Thermal Ionization Mass Spectrometry. International Journal of Mass Spectrometry, 2016, 404, pp.35 - 39. 10.1016/j.ijms.2016.04.005 . cea-03470752

\section{HAL Id: cea-03470752 \\ https://hal-cea.archives-ouvertes.fr/cea-03470752}

Submitted on 8 Dec 2021

HAL is a multi-disciplinary open access archive for the deposit and dissemination of scientific research documents, whether they are published or not. The documents may come from teaching and research institutions in France or abroad, or from public or private research centers.
L'archive ouverte pluridisciplinaire HAL, est destinée au dépôt et à la diffusion de documents scientifiques de niveau recherche, publiés ou non, émanant des établissements d'enseignement et de recherche français ou étrangers, des laboratoires publics ou privés. 


\title{
Contribution of the Faraday cup coupled to $10^{12}$ ohms current amplifier for uranium $235 / 238$ and $234 / 238$
} isotope ratio measurements by Thermal Ionization Mass Spectrometry

\author{
Alexandre Quemet*, Melody Maloubier and Alexandre Ruas \\ CEA, Nuclear Energy Division, RadioChemistry \& Processes Department, F-30207 Bagnols sur Cèze, France
}

* Corresponding author. E-mail address: alexandre.quemet@cea.fr (A. Quemet)

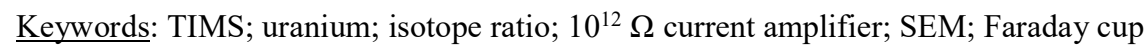

\section{$\underline{\text { Abstract: }}$}

This work highlights the possibility of improving, for given deposited quantities, the accuracy of uranium isotope ratio determination by Thermal Ionization Mass Spectrometry (TIMS) using Faraday cups coupled to a $10^{12} \Omega$ current amplifying system. This system improves the electronic sensitivity compared to the same Faraday cups coupled to $10^{11} \Omega$ current amplifiers. The analytical procedure developed in a previous work (Quemet et al., 2014) was applied in order to study the improvements in accuracy using the Faraday cups equipped with $10^{12} \Omega$ current amplifier. The ${ }^{234} \mathrm{U} /{ }^{238} \mathrm{U}$ and ${ }^{235} \mathrm{U} /{ }^{238} \mathrm{U}$ isotope ratios were measured on the Certified Reference Material IRMM 052 (natural uranium). Results were evaluated relying on NF T 90-210 norm regarding method validation. The ${ }^{234} \mathrm{U} /{ }^{238} \mathrm{U}$ and ${ }^{235} \mathrm{U} /{ }^{238} \mathrm{U}$ isotope ratios were studied by total evaporation using different configurations. First, ${ }^{234} \mathrm{U}$ or ${ }^{235} \mathrm{U}$ were measured with a Faraday cup coupled to a $10^{12} \Omega$ current amplifier and ${ }^{238} \mathrm{U}$ was measured with a Faraday cup coupled to a $10^{11} \Omega$ current amplifier. Then, ${ }^{234} \mathrm{U}$ or ${ }^{235} \mathrm{U}$ were measured by discrete dynodes electron multiplier and ${ }^{238} \mathrm{U}$ was measured with a Faraday cup coupled to a $10^{12} \Omega$ current amplifier. In comparison to the configurations using the $10^{11} \Omega$ current amplifier, the analyzable quantity was reduced from $250 \mathrm{ng}$ to $100 \mathrm{ng}$ for the ${ }^{235} \mathrm{U} /{ }^{238} \mathrm{U}$ isotope ratio and from $50 \mathrm{ng}$ to $3 \mathrm{ng}$ for the ${ }^{234} \mathrm{U} /{ }^{238} \mathrm{U}$ isotope ratio with extended uncertainty below $0.28 \%$ for the ${ }^{235} \mathrm{U} /{ }^{238} \mathrm{U}$ isotope ratio, in compliance with the International Target Values (ITV 2010), and below $5 \%$ for the ${ }^{234} \mathrm{U} /{ }^{238} \mathrm{U}$ isotope ratio.

\section{Introduction}

Accurate measurements for the uranium isotope ratios is well recognized in the nuclear field [1,2]. The ${ }^{235} U / 238 U$ isotope ratio allows determining the enrichment level of uranium. Safeguard authorities requirement for ${ }^{235} \mathrm{U}$ abundance measurement uncertainty by Thermal Ionization Mass Spectrometry (TIMS) is set to $0.28 \%(\mathrm{k}=1)$ [3]. The detection of ${ }^{234} U$ is of prime interest in nuclear forensics [4]. Also, for a given sample, the relative amount of ${ }^{234} \mathrm{U}$ dramatically changes its radiotoxicity [5]. However, the ${ }^{234} \mathrm{U}$ isotope abundance is generally very low $(0.1 \%$ of the total uranium $)$ in materials handled in the nuclear industry.

The accuracy (i.e. measurement trueness and precision) of low signal measurements (low analytes quantity or low isotope abundance) is limited by the detection system used for mass spectrometry. The emergence of high resistance amplifiers (i.e. coupled to $10^{12} \Omega$ or $10^{13} \Omega$ current amplifiers) allows the decrease of the analyzable quantity by TIMS [6-8]. The signal to noise ratio is in theory three times higher for the $10^{12} \Omega$ current amplifiers than for $10^{11} \Omega$ at a given ion current [9]. This study investigates the accuracy improvement for natural uranium isotope ratios using current amplifiers equipped with $10^{12} \Omega$ resistors. The study of the natural uranium is representative of a wide array of nuclear samples found in the nuclear industry: ${ }^{235} \mathrm{U}$ isotope abundance is between $3.2 \%$ and $4.4 \%$ for uranium used as fuel in light water reactor, and is as low as $0.2 \%$ for depleted uranium $[10,11]$. The ${ }^{234} \mathrm{U}$ isotope is enriched and depleted along the uranium cycle and in greater relative extent than the ${ }^{235} \mathrm{U}$ isotope [10]. 
In a previous study [1], the ${ }^{234} \mathrm{U} /{ }^{238} \mathrm{U}$ and ${ }^{235} \mathrm{U} /{ }^{238} \mathrm{U}$ isotope ratios were measured using Faraday cups equipped with a $10^{11} \Omega$ current amplifiers, discrete dynode secondary electron multipliers and continuous dynode electron multipliers. For the ${ }^{234} \mathrm{U} /{ }^{238} \mathrm{U}$ isotope ratio, the analyzable quantity was reduced from $1270 \mathrm{ng}$ down to $50 \mathrm{ng}$ with an enlarged uncertainty lower than $5 \%$, by using electron multipliers compared to a configuration using only Faraday cups equipped with $10^{11} \Omega$ current amplifiers. In that previous work [1], the lowest analyzable quantity for the ${ }^{235} \mathrm{U} /{ }^{238} \mathrm{U}$ isotope ratio $(50 \mathrm{ng}$ ) was achieved by peak-jumping measurement using discrete dynode secondary electron multipliers. For the ${ }^{235} \mathrm{U} /{ }^{238} \mathrm{U}$ isotope ratio determination with the total evaporation method, the lowest analyzable quantity was equal to $250 \mathrm{ng}$ for a configuration using only Faraday cups equipped with $10^{11} \Omega$ current amplifiers [1]. For all the experiments where the target accuracy was achieved, the calculated uncertainties were below $0.28 \%$ for the ${ }^{235} \mathrm{U} /{ }^{238} \mathrm{U}$ isotope ratio, in compliance with the International Target Value [3], and below $5 \%$ for the ${ }^{234} \mathrm{U} /{ }^{238} \mathrm{U}$ isotope ratio.

This present study aims to continue the previous work [1], by studying the improvements in accuracy using a Faraday cup coupled to $10^{12} \Omega$ current amplifier for the ${ }^{234} \mathrm{U} /{ }^{238} \mathrm{U}$ and ${ }^{235} \mathrm{U} /{ }^{238} \mathrm{U}$ uranium isotope ratios measurements. The results obtained with the different configurations using discrete dynode electron multiplier and Faraday cups coupled to $10^{11}$ and $10^{12} \Omega$ current amplifiers were discussed in terms of measurement trueness and precision in order to determine the best and most simple analytical method. The results of analyses using the $10^{12} \Omega$ current amplifiers were compared to those obtained with the conventional $10^{11} \Omega$ current amplifiers. The results were evaluated according to the NF T 90-210 norm regarding method validation [12].

\section{Experimental}

Experimental details were described in Quemet et al. [1]. Compared to the previously published studies [1,13], the Thermo Scientific Triton Thermal Ionization Mass Spectrometer was upgraded with two Faraday cups. The instrument is now equipped with 9 movable Faraday cups which can be coupled to $10^{11} \Omega$ current amplifiers $(9$ available and hereafter referred to as FC $10^{11}$ ) or a $10^{12} \Omega$ current amplifier (1 available and hereafter referred to as FC $10^{12}$ ), one fixed discrete dynode Secondary Electron Multiplier (hereafter referred to as SEM in agreement with Thermo Scientific denomination), located behind the central Faraday cup, and 3 movable continuous dynode electron multipliers operated in ion counting mode (hereafter referred to as MIC in agreement with Thermo Scientific denomination). The SEM is combined with a RPQ retardation filter to improve the abundance sensitivity to about $10 \mathrm{ppb}$ at mass $\mathrm{M}$ compared to mass $\mathrm{M}+1$ or $\mathrm{M}-1$.

A double Re-filament configuration was used to control independently the evaporation and the ionization temperature. These filaments (Re metal, purity $99.99 \%$ ) are provided by ATES. $1 \mu \mathrm{L}$ of solution was deposited onto the filament previously outgassed. After deposition, the sample was dried with a $0.5 \mathrm{~A}$ current. Then the current was progressively increased from $0.5 \mathrm{~A}$ to $2 \mathrm{~A}$ in $10 \mathrm{~s}$ and was maintained at $2 \mathrm{~A}$ for $5 \mathrm{~s}$.

Two different methods were used to measure the uranium isotope ratios: the total evaporation method and the classical method. In the total evaporation method, the ion beams coming from the uranium isotopes are collected by a multi-collection system until the sample is fully evaporated. This method was developed in order to overcome mass fractionation, the main cause of the TIMS measurement bias. In the classical or traditional method, the different isotopes are collected in a limited period of the sample evaporation. Then the isotope ratios are corrected of the mass fractionation by using an external normalization. This method is available in single or multi-collection mode. These two methods are described in detail in Quemet et al. [1].

The measurements performed with the SEM and the MIC in the previous study showed comparable results [1]. However, using a SEM is easier and the signal was more stable over time. Therefore, in the present study, the isotope ratio measurements using electron multipliers were only performed using the discrete dynode multipliers.

The method evaluation, according to the NF T 90-210 norm, is described at length in the previous study $[1,12]$. We recall the main calculations steps: a maximal bias (MB) was set by the Laboratory of Analysis and Materials Metrology (LAMM) at $0.28 \%$ when isotope ratio involved the two most abundant isotopes $\left({ }^{238} \mathrm{U}\right.$ and $\left.{ }^{235} \mathrm{U}\right)$ to satisfy the International Target Value (ITV) recommended by the IAEA [3] and $5 \%$ when isotope ratio involved ${ }^{234} \mathrm{U}$ and ${ }^{238} \mathrm{U}$. For each method and each uranium quantity, five independent determinations were performed. 
The precision control consisted in verifying the repeatability, given by the relative standard deviation (RSD). The relative bias, or measurement trueness, of the method was calculated using formula 1 :

$$
\operatorname{Bias}(\%)=\frac{|Z-r e f|}{r e f} \times 100
$$

Where $\mathrm{Z}$ is the average of the series and ref is the certified value of the reference.

Finally, the method was validated in terms of accuracy when the following inequality was verified:

$$
|Z-r e f|+2 \times s<M B
$$

Where $\mathrm{s}$ is the standard deviation of the series.

According to the NF T 90-210 norm, equation (3), where $u_{r e f}$ is the uncertainty at $k=1$ of the reference value and NB is the normalized bias, was used to determine whether the analytical method has a statistically significant bias or not. If $\mathrm{NB}>2$, the method is considered having a statistically significant bias.

$$
N B=\frac{|Z-r e f|}{\sqrt{s^{2}+u_{r e f}^{2}}}
$$

The uncertainty estimations (Figure 1, Tables S1 and S2 in supplementary materials) take into account the standard deviation, the method bias and the reference value uncertainty.

3. Results and discussion

Uranium isotope measurements have been performed with quantities varying from $1270 \mathrm{ng}$ down to $1 \mathrm{ng}$. Five measurements were performed for the different quantities and measurement methods. The ${ }^{234} U /{ }^{238} U$ and ${ }^{235} \mathrm{U} /{ }^{238} \mathrm{U}$ isotope ratios were determined by total evaporation method using two different detector configurations: FC $10^{12} / \mathrm{FC} 10^{11}$ and SEM / FC $10^{12}$. The ${ }^{234} \mathrm{U} /{ }^{238} \mathrm{U}$ isotope ratio was also determined by the classical method using peak-jumping SEM measurement.

Table 1, Table 2, Figure 1 and supplementary materials report the results obtained for the ${ }^{234} U /{ }^{238} U$ and ${ }^{235} U /{ }^{238} U$ isotope ratios for each deposited quantity.

3.1. ${ }^{234} \mathrm{U} /{ }^{238} \mathrm{U}$ isotope ratio measurements

3.1.1. Total evaporation method using Faraday cups coupled to $10^{12} \Omega\left({ }^{234} \mathrm{U}\right)$ and $10^{11} \Omega\left({ }^{238} \mathrm{U}\right)$ current amplifiers

${ }^{234} \mathrm{U} /{ }^{238} \mathrm{U}$ isotope ratio measurements have been performed using $\mathrm{FC} 10^{12}$ to measure ${ }^{234} \mathrm{U}$ and $\mathrm{FC} 10^{11}$ to measure ${ }^{238} \mathrm{U}$ (Table 1 and Figure 1). The measurement trueness was lower than $5 \%$ for $1270 \mathrm{ng}(2.0 \%), 250 \mathrm{ng}$ $(1.1 \%)$ and $100 \mathrm{ng}(1.7 \%)$. The observed relative standard deviations (RSD) of the ${ }^{235} \mathrm{U} /{ }^{238} \mathrm{U}$ isotope ratio were $1.0 \%$ for $1270 \mathrm{ng}, 1.9 \%$ for $250 \mathrm{ng}$ and $7.4 \%$ for $100 \mathrm{ng}$. The RSD for a uranium quantity of $100 \mathrm{ng}$ is higher than the set maximum bias (5\%). The decrease in precision found for loadings filament with $100 \mathrm{ng}$ led us to exclude such low filament loadings from validation. That is why this method was validated for uranium quantities from 1270 down to $250 \mathrm{ng}$.

3.1.2. Total evaporation method using SEM $\left({ }^{234} \mathrm{U}\right)$ and Faraday cup coupled to $10^{12} \Omega$ current amplifier $\left({ }^{238} \mathrm{U}\right)$

One of the limitations of measuring ${ }^{234} \mathrm{U}$ with a FC $10^{12}$ is that the measured signal becomes very low when the deposited quantities decrease down to $100 \mathrm{ng}$. For instance, the ${ }^{234} \mathrm{U}$ signal measured with a FC $10^{12}$ was around 
$0.8 \mathrm{mV}$ for a uranium quantity of $100 \mathrm{ng}$ which is too low for a good repeatability. However, the same ${ }^{234} \mathrm{U}^{+}$ion beam measured with a SEM corresponds to $4800 \mathrm{cps}$, which is enough for a good measurement repeatability. Hence, in order to improve the accuracy on the ${ }^{234} \mathrm{U} /{ }^{238} \mathrm{U}$ isotope ratio determination, measurements have also been performed using the SEM to measure ${ }^{234} \mathrm{U}$ and FC $10^{12}$ to measure ${ }^{238} \mathrm{U}$ as an extension of our previous work [1] where the SEM was used for ${ }^{234} \mathrm{U}$ and FC $10^{11}$ for ${ }^{238} \mathrm{U}$ (Table 1 and Figure 1).

Unlike the previous study [1], the signal intensity for the target isotope needed to be adjusted. One of the limitations of the Thermo Triton $10^{12} \Omega$ current amplifying system is that the maximum measuring signal is set at $5 \mathrm{~V}$ (instead of $50 \mathrm{~V}$ for the $10^{11} \Omega$ current amplifier). For the uranium analysis of a $50 \mathrm{ng}$ deposit, a relatively low signal (about $1500 \mathrm{cps}$ ) was measured for the ${ }^{234} \mathrm{U}$ isotope (SEM), corresponding to a signal as high as $4.5 \mathrm{~V}$ for the ${ }^{238} \mathrm{U}$ isotope ( $\mathrm{FC} 10^{12}$ ). Therefore, it was hardly possible to analyze uranium quantity higher than $50 \mathrm{ng}$ with a $\mathrm{FC} 10^{12}$. In essence, these considerations suggest that it would have been better combining SEM with FC $10^{11}$ (as done in the previous study [1]), allowing higher count rates for ${ }^{234} \mathrm{U}$ on the SEM. But the obtained results show, for deposited quantities below $50 \mathrm{ng}$, it is better to combine the SEM with FC $10^{12}$.

For $50 \mathrm{ng}(\mathrm{bias}=0.1 \%$ and $\mathrm{RSD}=0.4 \%), 10 \mathrm{ng}(\mathrm{bias}=0.01 \%$ and $\mathrm{RSD}=1.5 \%)$ and $3 \mathrm{ng}(\mathrm{bias}=0.2 \%$ and $\mathrm{RSD}=1.2 \%$ ), the measurement trueness and the RSD were lower than $5 \%$ (Table 1). For a deposit quantity of $1 \mathrm{ng}$, the measurement trueness increased and was higher than $5 \%$. As a consequence, the method accuracy was validated for uranium quantities between 50 and $3 \mathrm{ng}$.

It should be noticed, the measurement trueness obtained with the SEM (between $0.0 \%$ and $0.2 \%$ for this study and between $0.1 \%$ and $0.9 \%$ for the previous study [1]) was systematically better than the measurement trueness obtained with the Faraday cups (between 1.1 and $2.0 \%$ for this study and $1.1 \%$ for the previous one [1]). This difference can be explained by the peak tailing effect. The SEM was combined with a RPQ retardation filter to decrease the abundance sensitivity contribution of the ${ }^{238} \mathrm{U}$ and ${ }^{235} \mathrm{U}$ on the ${ }^{234} \mathrm{U}$ signal. The Faraday cup is not equipped with such system. That generated in an important contribution of the ${ }^{238} U$ and ${ }^{235} U$ on the ${ }^{234} U$ signal and a higher bias on the ${ }^{234} \mathrm{U} /{ }^{238} \mathrm{U}$ isotope ratio measurement. Unfortunately, further peak tailing correction was not possible with the total evaporation method, as it is one of its limitation [2,14]. A solution for further peak tailing correction would be using the modified total evaporation (MTE) [2,15-17]. The MTE interrupts the total evaporation process regularly in order to correct the peak tailing, check the peak centering, refocus the ion beam or measure the SEM/FC inter-calibration gain. It improves the accuracy of the minor ratios determinations [2,14]. However, the MTE requires larger sample quantity and the analysis time increases significantly, making its application difficult in analysis routine [2].

\subsubsection{Classical method using peak-jumping SEM measurement}

We have shown in our previous work that, to decrease the analyzable quantities to very low levels, peak-jumping with SEM could be used [1]. However, using the peak-jumping method to obtain the ${ }^{234} \mathrm{U} /{ }^{238} \mathrm{U}$ directly is not possible as the signal would be either too low for ${ }^{234} \mathrm{U}$ on the SEM or too high for ${ }^{238} \mathrm{U}$ on the same detector. We attempted an indirect method for the ${ }^{234} \mathrm{U} /{ }^{238} \mathrm{U}$ isotope ratio measurement for uncertainties improvements. ${ }^{234} \mathrm{U} /{ }^{235} \mathrm{U}$ isotope ratio measurements have been performed by the classical method using the peak-jumping measurements and the SEM to measure ${ }^{234} \mathrm{U}$ and ${ }^{235} \mathrm{U}$. In that case, the ${ }^{234} \mathrm{U} /{ }^{238} \mathrm{U}$ isotope ratio could be calculated from the measurement of the ${ }^{235} \mathrm{U} /{ }^{238} \mathrm{U}$ isotope ratio by another method such as the classical method with peakjumping SEM measurement. The experiment was performed on the smallest analyzable quantity where the accuracy criterion was achieved for the ${ }^{234} \mathrm{U} /{ }^{238} \mathrm{U}$ ratio $(3 \mathrm{ng}$, see section 3.1.2). For this quantity, the bias $(0.9 \%)$ and the $\operatorname{RSD}(0.8 \%)$ for the ${ }^{234} \mathrm{U} /{ }^{235} \mathrm{U}$ ratio measurement using the peak-jumping method were acceptable. But these performances could not lead to an improvement of the ${ }^{234} \mathrm{U} /{ }^{238} \mathrm{U}$ ratio determination obtained in section 3.1.2, considering the ${ }^{235} \mathrm{U} /{ }^{238} \mathrm{U}$ relative uncertainty that can be achieved (in previous work determined to $4.1 \%(\mathrm{k}=2)$ at $3 \mathrm{ng}$ [1]). For a lower uranium quantity of $1 \mathrm{ng}$, the ${ }^{235} \mathrm{U} /{ }^{238} \mathrm{U}$ relative uncertainty obtained in previous work was too high, way more than $5 \%(189 \%, \mathrm{k}=2)$ [1]. To conclude, peak-jumping, even while using an indirect method, was not suited for determining the ${ }^{234} \mathrm{U} /{ }^{238} \mathrm{U}$ ratio.

\section{2. ${ }^{235} \mathrm{U} /{ }^{238} \mathrm{U}$ isotope ratio measurements}


3.2.1. Total evaporation method using Faraday cups coupled to $10^{12} \Omega\left({ }^{235} \mathrm{U}\right)$ and $10^{11} \Omega\left({ }^{238} \mathrm{U}\right)$ current amplifiers

${ }^{235} \mathrm{U} /{ }^{238} \mathrm{U}$ isotope ratio measurements have been performed using $\mathrm{FC} 10^{12}$ to measure ${ }^{235} \mathrm{U}$ and $\mathrm{FC} 10^{11}$ to measure ${ }^{238} \mathrm{U}$ for uranium quantities varying from $1270 \mathrm{ng}$ down to $50 \mathrm{ng}$ (Table 2 and Figure 1). The measurement trueness for a quantity of $1270 \mathrm{ng}(0.01 \%), 250 \mathrm{ng}(0.09 \%), 100 \mathrm{ng}(0.03 \%)$ and $50 \mathrm{ng}(0.11 \%)$ was less than $0.28 \%$. A degradation of the repeatability was observed for a deposited quantity of $50 \mathrm{ng}$. Due to the degradation of the repeatability for the quantity of $50 \mathrm{ng}$, the method was inaccurate for this quantity in terms of ITV achievements. Thus, the method was validated for uranium quantities from $1270 \mathrm{ng}$ down to $100 \mathrm{ng}$.

3.2.2. Total evaporation method using SEM $\left({ }^{235} \mathrm{U}\right)$ and Faraday cup coupled to $10^{12} \Omega$ current amplifier $\left({ }^{238} \mathrm{U}\right)$

${ }^{235} \mathrm{U} /{ }^{238} \mathrm{U}$ isotope ratio measurements have been performed by total evaporation method using the SEM to measure ${ }^{235} \mathrm{U}$ and FC $10^{12}$ to measure ${ }^{238} \mathrm{U}$ (Table 2 and Figure 1). For a $50 \mathrm{ng}$ deposit, the measurement trueness was lower than $0.28 \%$. However, the repeatability was poor $(1.2 \%)$. Therefore, the method accuracy was not validated for a maximum bias set at $0.28 \%$. In the previous study, the low repeatability of the isotope ratio measurement was assumed as a consequence of the low signal $(300 \mathrm{mV})$ collected on the FC $10^{11}$, which can deteriorate its relative stability. In the present work, the signal collected on the FC $10^{12}(3 \mathrm{~V})$ was very comfortable. However, the repeatability was not improved using a Faraday cup, showing it was not the source of the poor measurement repeatability (present and previous work). This lack of repeatability is probably due to the SEM instability. The SEM/FC inter-calibration gains variation before and after the ${ }^{235} \mathrm{U} /{ }^{238} \mathrm{U}$ isotope ratio measurement were between $0.1 \%$ and $1.3 \%$ in this study. Also, during an analysis, the gain fluctuated without following a specific predictable trend (Figure S1 in supplementary materials). To conclude, the use of the SEM as one of the detectors in the total evaporation method was not compatible with achieving very low uncertainties satisfying the ITV. In order to obtain a low measurement uncertainty using the SEM detector, a measurement by peak-jumping was more suitable as it did not require yield determination and counterbalanced the SEM instability [18]. This consideration was confirmed by the very low uncertainties obtained in our previous work for the ${ }^{235} \mathrm{U} /{ }^{238} \mathrm{U}$ ratio determination using the peak-jumping protocol. Replacing total evaporation method by peak-jumping replaces the uncertainty arising from detector inter-calibration by the time dependent isotope fractionation. However, the isotope fractionation can be partly corrected using the mass fractionation factor determined with certified reference materials analyzed in the same condition. Finally, this is why, our studies led to lower uncertainties with the peak-jumping $\left({ }^{235} \mathrm{U}\right.$ : SEM $/{ }^{238} \mathrm{U}$ : SEM) compared to the total evaporation $\left({ }^{235} \mathrm{U}\right.$ : SEM / $\left.{ }^{238} \mathrm{U}: \mathrm{FC}\right)$.

\section{Conclusion}

This study complements the previous work [1] and presents the advantages of using $\mathrm{FC} 10^{12}$ in complement of FC $10^{11}$, SEM and MIC. The ${ }^{235} \mathrm{U} /{ }^{238} \mathrm{U}$ and ${ }^{234} \mathrm{U} /{ }^{238} \mathrm{U}$ isotope ratios were studied in terms of measurement trueness, precision and accuracy according to the NF T 90-210 norm. Figure 2, Table S3 and Table S4 in the supplementary materials summarizes the combined results for both current and previous work and shows the mass range where the aimed accuracy was achieved and the related TIMS detectors configuration. The figure shows that using FC $10^{12}$ decreases substantially the possible amount of uranium deposit leading to validated results. For the sake of simplicity in the measuring protocol and also considering the detectors lifespan (Faraday cups > SEM > MIC), in a uranium quantity range where both SEM and MIC lead to validated results, it is advised to use the SEM. Also, in a uranium quantity region where both SEM and FC $10^{12}$ lead to validated results, it is advised to use the $\mathrm{FC} 10^{12}$.

Acknowledgements: We are grateful to S. Baghdadi (CEA/MAR/DEN/DRCP/SERA/LAMM) for her precious advice on the present paper, V. Dalier (CEA/MAR/DEN/DRCP/SERA/LAMM) for his help on the TIMS and all the reviewers of the present manuscript for their precious advice and comments. 
Bibliography

[1] A. Quemet, M. Maloubier, V. Dalier and A. Ruas, Development of an analysis method of minor uranium isotope ratio measurements using electron multipliers in thermal ionization mass spectrometry, Int. J. Mass Spectrom. 374 (2014) 26-32.

[2] S.K. Aggarwal, Thermal ionisation mass spectrometry (TIMS) in nuclear science and technology - a review, Anal. Methods. 8 (2016) 942-957.

[3] International Atomic Energy Agency, International Target Values 2010 for Measurement Uncertainties in Safeguarding Nuclear Materials - STR368, Vienna, Austria, 2010.

[4] C. Venchiarutti, Z. Varga, S. Richter, R. Jakopič, K. Mayer and Y. Aregbe, REIMEP-22 inter-laboratory comparison: "U Age Dating - determination of the production date of a uranium certified test sample," Radiochim. Acta. (2015) 1-10.

[5] M.-T. Ménager, J. Garnier-Laplace and M. Goyffron, Toxicologie nucléaire environnementale et humaine, Chap. 23, in: Lavoisier, 2009: pp. 405-437.

[6] J.M. Koornneef, C. Bouman, J.B. Schwieters and G.R. Davies, Use of 10(12) ohm current amplifiers in $\mathrm{Sr}$ and $\mathrm{Nd}$ isotope analyses by TIMS for application to sub-nanogram samples, J. Anal. At. Spectrom. 28 (2013) 749.

[7] D. Wielandt and M. Bizzarro, A TIMS-based method for the high precision measurements of the threeisotope potassium composition of small samples, J. Anal. At. Spectrom. 26 (2011) 366.

[8] D. Tuttas, J. Schwieters, N. Quaas, C. Bouman and T.F. Scientific, Improvements in TIMS High Precision Isotope Ratio Measurements for Small Sample Sizes, Thermo Fisher Scientific, Bremen, Germany, (2007) vol. application note: 30136.

[9] M.E. Wieser and J.B. Schwieters, The development of multiple collector mass spectrometry for isotope ratio measurements, Int. J. Mass Spectrom. 242 (2005) 97-115.

[10] S.L. Ziegler and B.A. Bushaw, Ultratrace uranium fingerprinting with isotope selective laser ionization spectrometry., Anal. Chem. 80 (2008) 6029-6033.

[11] M. Krachler and P. Carbol, Validation of isotopic analysis of depleted, natural and enriched uranium using high resolution ICP-OES, J. Anal. At. Spectrom. 26 (2011) 293-299.

[12] AFNOR, NF T90-210 norm : Water quality - Protocol for the intial method performance assesment in a laboratory, 2009.

[13] A. Quemet, C. Maillard and A. Ruas, Determination of zirconium isotope composition and concentration for nuclear sample analysis using Thermal Ionization Mass Spectrometry, Int. J. Mass Spectrom. 392 (2015) 34-40.

[14] K.J. Mathew and A. Haoszbek, Comparison of mass spectrometric methods (TE, MTE and conventional) for uranium isotope ratio measurements, J. Radioanal. Nucl. Chem. 307 (2016) 16811687.

[15] S. Richter and S.. Goldberg, Improved techniques for high accuracy isotope ratio measurements of nuclear materials using thermal ionization mass spectrometry, Int. J. Mass Spectrom. 229 (2003) 181197.

[16] S. Richter, H. Kühn, Y. Aregbe, M. Hedberg, J. Horta-Domenech, K. Mayer, E. Zuleger, S. Bürger, S. Boulyga, A. Köpf, J. Poths and K. Mathew, Improvements in routine uranium isotope ratio measurements using the modified total evaporation method for multi-collector thermal ionization mass spectrometry, J. Anal. At. Spectrom. 26 (2011) 550-564.

[17] S. Bürger, S.D. Balsley, S. Baumann, J. Berger, S.F. Boulyga, J.A. Cunningham, S. Kappel, A. Koepf and J. Poths, Uranium and plutonium analysis of nuclear material samples by multi-collector thermal ionisation mass spectrometry: Quality control, measurement uncertainty, and metrological traceability, Int. J. Mass Spectrom. 311 (2012) 40-50.

[18] D.L. Hoffmann, J. Prytulak, D.A. Richards, T. Elliott, C.D. Coath, P.L. Smart and D. Scholz, Procedures for accurate $\mathrm{U}$ and $\mathrm{Th}$ isotope measurements by high precision MC-ICPMS, Int. J. Mass Spectrom. 264 (2007) 97-109. 


\begin{tabular}{ccccc}
\hline Quantity (ng) & ${ }^{234} \mathrm{U} /{ }^{238} \mathrm{U}$ & Measurement trueness $(\%)$ & RSD $(\%)$ & Accuracy \\
\hline Total evaporation using Faraday cup with & $10^{12} \Omega\left({ }^{234} \mathrm{U}\right)$ and $10^{11} \Omega\left({ }^{238} \mathrm{U}\right)$ & current amplifiers & \\
1270 & 0.00005657 & 2.0 & 1.0 & Valid \\
250 & 0.00005611 & 1.1 & 1.9 & Valid \\
100 & 0.00005641 & 1.7 & 7.4 & Not valid \\
\hline Total evaporation & using $S E M\left({ }^{234} \mathrm{U}\right)$ & and Faraday cup & with $10^{12} \Omega$ current amplifiers $\left.{ }^{238} \mathrm{U}\right)$ & \\
50 & 0.00005556 & 0.1 & 0.4 & Valid \\
10 & 0.00005547 & 0.0 & 1.5 & Valid \\
3 & 0.00005539 & 0.2 & 1.2 & Valid \\
1 & 0.00005838 & 5.2 & 1.9 & Not valid \\
\hline
\end{tabular}

Table 1: ${ }^{234} \mathrm{U} /{ }^{238} \mathrm{U}$ isotope ratio results obtained with different methods and deposited amounts. For each determination five measurements have been performed (certified value: $0.00005548 \pm 0.00000022, \mathrm{k}=2$ ). The accuracy is considered valid or not valid according to the NF T 90-210 norm $[1,12]$.

\begin{tabular}{ccccc}
\hline Quantity (ng) & ${ }^{235} \mathrm{U} /{ }^{238} \mathrm{U}$ & Measurement trueness $(\%)$ & RSD $(\%)$ & Accuracy \\
\hline Total evaporation using Faraday cup & with $10^{12} \Omega\left({ }^{235} \mathrm{U}\right)$ and $10^{11} \Omega\left({ }^{238} \mathrm{U}\right)$ & current amplifiers & \\
1270 & 0.0072711 & 0.01 & 0.07 & Valid \\
250 & 0.0072655 & 0.09 & 0.07 & Valid \\
100 & 0.0072737 & 0.03 & 0.07 & Valid \\
50 & 0.0072637 & 0.11 & 0.15 & Not valid \\
\hline Total evaporation using & $S E M\left({ }^{335} U\right)$ and Faraday cup with $10^{12} \Omega$ current amplifiers $\left.{ }^{238} U\right)$ & \\
50 & 0.0072841 & 0.17 & 1.22 & Not valid \\
\hline
\end{tabular}

Table 2: ${ }^{235} \mathrm{U} /{ }^{238} \mathrm{U}$ isotope ratio results obtained with different methods and deposited amounts. For each determination five measurements have been performed (certified value: $0.0072718 \pm 0.0000030, k=2$ ).

The accuracy is considered valid or not valid according to the NF T 90-210 norm $[1,12]$. 
${ }^{234} U /{ }^{238} U$ isotope ratio

a) FC $10^{12}\left({ }^{234} U\right) / F C 10^{11}\left({ }^{238} U\right)$

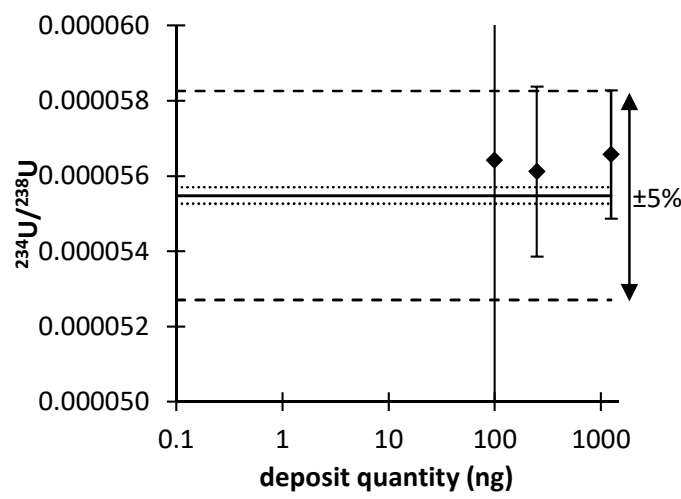

b) SEM $\left({ }^{234} \mathrm{U}\right) / \mathrm{FC} 10^{12}\left({ }^{238} \mathrm{U}\right)$

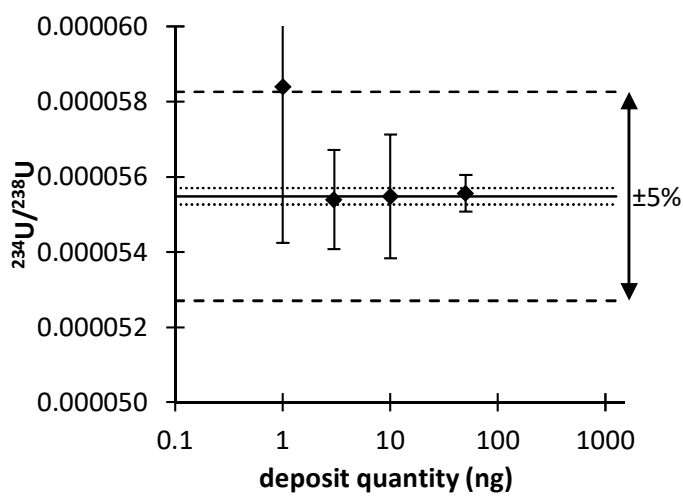

${ }^{235} \mathrm{U} /{ }^{238} \mathrm{U}$ isotope ratio

c) FC $10^{12}\left({ }^{235} \mathrm{U}\right) / \mathrm{FC} 10^{11}\left({ }^{238} \mathrm{U}\right)$

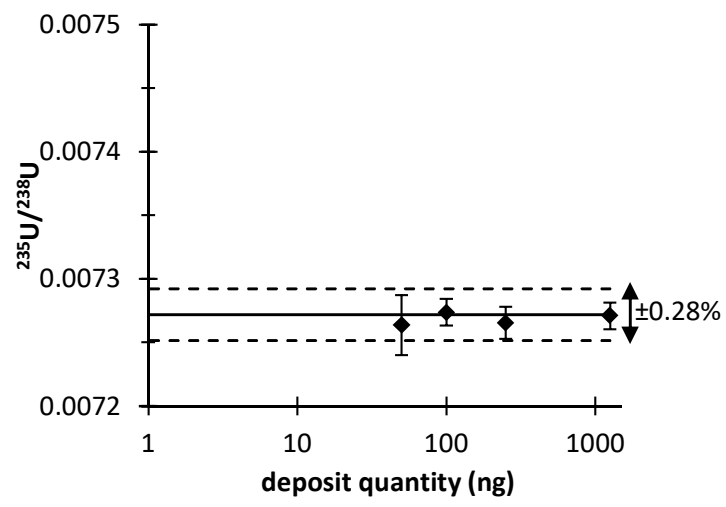

d) SEM $\left({ }^{235} U\right) /$ FC $10^{12}\left({ }^{238} U\right)$

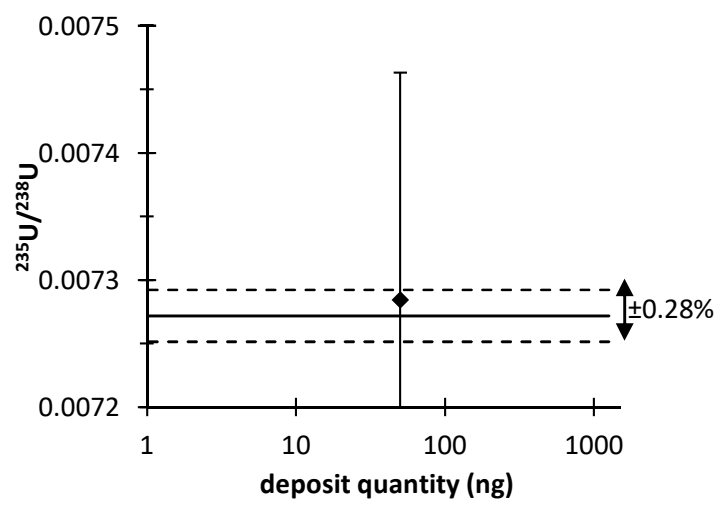

Figure 1: Results for the ${ }^{234} \mathrm{U} /{ }^{238} \mathrm{U}$ isotope ratio measurements by total evaporation method using Faraday cups coupled to $10^{12} \Omega\left(\mathrm{FC} 10^{12}\right), 1^{11} \Omega$ current amplifiers $\left(\mathrm{FC} 10^{11}\right)$ and the SEM (a and b) and results for the ${ }^{235} U /{ }^{238} \mathrm{U}$ isotope ratio measurements by total evaporation method using Faraday cups coupled to $10^{12} \Omega, 10^{11} \Omega$ current amplifiers and the SEM (c and d). Each point is represented with a $95 \%$ coverage factor uncertainty $(\mathrm{k}=2)$. The dark line (-) corresponds to the reference value and the dotted line (...) represents its uncertainty at $k=2$ (not represented for better clarity for the isotope ratio ${ }^{235} U{ }^{238} U$ ): $0.0072718 \pm 0.00000030$ for the ${ }^{235} U /{ }^{238} U$ isotope ratio and $0.00005548 \pm 0.00000022$ for the ${ }^{234} U /{ }^{238} U$ isotope ratio. The prolonged dotted line (- - ) represents the maximal bias fixed by the laboratory. 
a) ${ }^{234} \mathrm{U} /{ }^{238} \mathrm{U}$ isotope ratio
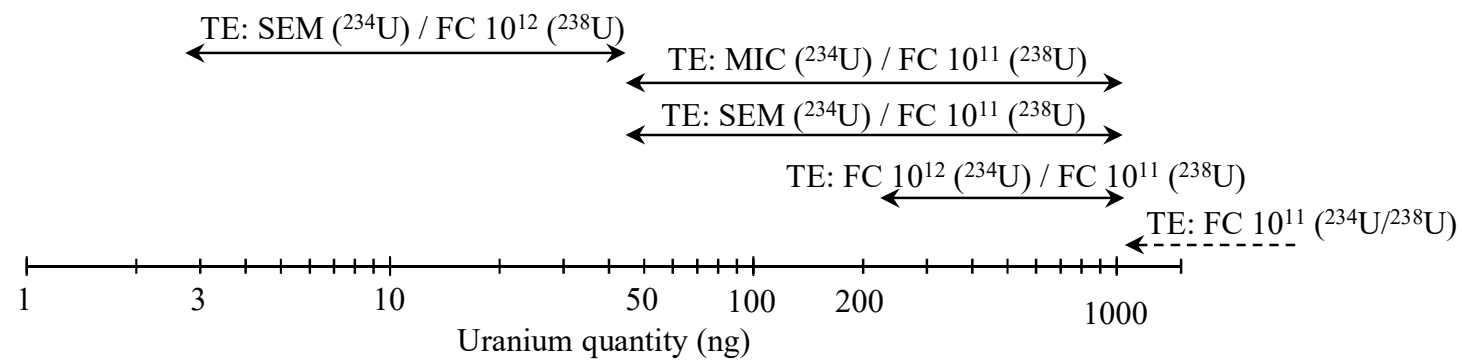

b) ${ }^{235} \mathrm{U} /{ }^{238} \mathrm{U}$ isotope ratio

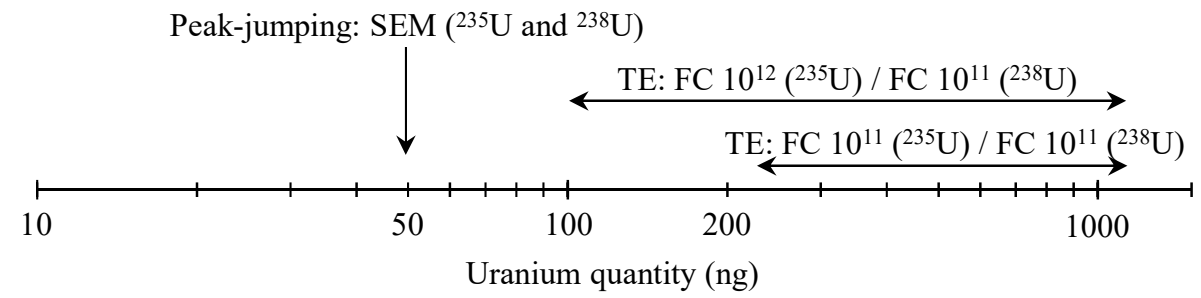

Figure 2: Synthesis of the mass range where the target accuracy was achieved for the determination of the ${ }^{234} U /{ }^{238} \mathrm{U}$ and ${ }^{235} \mathrm{U} /{ }^{238} \mathrm{U}$ isotope ratio in this study and in the previous one [1]: the configurations may use

Faraday cup with $10^{11} \Omega\left(\right.$ FC $\left.10^{11}\right)$ and $10^{12} \Omega\left(\right.$ FC 10 $\left.{ }^{12}\right)$ current amplifiers, SEM and MIC. The determination can be by the total evaporation method (TE) or by peak-jumping. 